九州大学学術情報リポジトリ

Kyushu University Institutional Repository

\title{
Temperature and Velocity Changes Across Tube Banks in One-directional and Bi-directional Flow Conditions
}

Hasbul lah, Nur jannah

Fakulti Kejuruteraan Mekanikal (FKM), Universiti Teknikal Malaysia Melaka (UTeM)

Fat imah Al Zahrah Mohd Saat

Fakulti Kejuruteraan Mekanikal (FKM), Universiti Teknikal Malaysia Melaka (UTeM)

Fadhi lah Shikh Anuar

Centre for Advanced Research on Energy, Universiti Teknikal Malaysia Melaka (UTeM)

Johari, Dahlia

Fakulti Kejuruteraan Mekanikal (FKM), Universiti Teknikal Malaysia Melaka (UTeM)

他

https://doi.org/10.5109/4480725

出版情報 : Evergreen. 8 (2)，pp.428-437，2021-06. Transdisciplinary Research and Education Center for Green Technologies, Kyushu University

バージョン :

権利関係 : 


\title{
Temperature and Velocity Changes Across Tube Banks in One- directional and Bi-directional Flow Conditions
}

\author{
Nurjannah Hasbullah ${ }^{1,2}$, Fatimah Al Zahrah Mohd Saat ${ }^{1,2,3, *}$, \\ Fadhilah Shikh Anuar ${ }^{2,4}$, Dahlia Johari, ${ }^{1,5}$, Mohamad Firdaus Sukri ${ }^{1,2}$. \\ ${ }^{1}$ Fakulti Kejuruteraan Mekanikal (FKM), Universiti Teknikal Malaysia Melaka (UTeM), Hang Tuah Jaya, \\ 76100 Durian Tunggal, Melaka, Malaysia. \\ ${ }^{2}$ Centre for Advanced Research on Energy, Universiti Teknikal Malaysia Melaka (UTeM), Hang Tuah \\ Jaya, 76100 Durian Tunggal, Melaka, Malaysia. \\ ${ }^{3}$ Green Design \& Manufacture Research Group, Center of Excellence Geopolymer \& Green Technology, \\ Universiti Malaysia Perlis (UniMAP), Malaysia. \\ ${ }^{4}$ Fakulti Teknologi Kejuruteraan Mekanikal dan Pembuatan (FTKMP), Universiti Teknikal Malaysia Melaka \\ (UTeM), Hang Tuah Jaya, 76100 Durian Tunggal, Melaka, Malaysia. \\ ${ }^{5}$ Akademi Laut Malaysia (ALAM), Batu 30, Kampung Tanjung Dahan, 78200 Kuala Sungai Baru, Melaka, \\ Malaysia.
}

*Author to whom correspondence should be addressed:

E-mail: fatimah@utem.edu.my

(Received January 7, 2021; Revised April 26, 2021; accepted April 26, 2021).

\begin{abstract}
The back-and-forth movement of flow in oscillatory flow condition that can be found in blood flow, thermoacoustic energy system and ocean wave can be categorized as bi-directional flow condition and heat transfer in this flow condition is not well understood. This paper reports an experimental investigation that compares temperature and velocity values between the onedirectional (the usual flow condition) and the bi-directional flow conditions. The experiment was done using thermoacoustic's standing wave rig with two different drivers to drive the one-directional flow and bi-directional flow conditions in the test rig. Results, that were recorded using piezoresistive pressure sensor, type-K thermocouple and hotwire anemometer, indicate that care should be exercised when calculating heat transfer in bi-directional flow conditions as the temperature and velocity changes are different compared to the one-directional flow condition. Differences were recorded to be within the range of $77 \%$ for temperature and $59.5 \%$ for velocity, presumably due to the different behavior of forced and natural convection effect as flow conditions changed.
\end{abstract}

Keywords: tube banks, oscillatory flow, heat transfer, thermoacoustic technology.

\section{Introduction}

In recent years, technology has evolved rapidly due to demanding human needs. Technology developments in the current era of ageing world requires careful attention on the environmental impact of the technology $y^{1,2,3)}$. This involves the effort to reduce greenhouse effects ${ }^{4}$, utilizing wasted heat from the currently available technology5), changing the working mechanism and working fluids so that pollution can be reduced ${ }^{6,7)}$, and improving system's performances to avoid too many losses to environment ${ }^{8}$. The rapid development of technology creates huge number of challenges for cooling technology as heat needs to be taken out of most of the energy system in order for the system to perform at their best. Tube banks are the most common arrangement found in many heat exchangers $^{9,10)}$. The heat transfer performance changes with the change of flow directions. In some applications like blood flow ${ }^{11)}$, thermoacoustic engine ${ }^{12)}$ or cooler/ocean flow ${ }^{13)}$, the fluid flows are not the usual steady one-directional type of flows. The fluid in these cases is flowing in oscillatory flow conditions which can be described as bi-directional flow condition as the fluid flows back and forth in cyclic nature. It is found, however, that the fundamental understandings of heat transfer in flows other than the steady one-directional flow conditions are scarce ${ }^{14)}$. Fig. 1 shows the illustration of one-directional flow and bi-directional flow conditions over a tube bank structure. In most devices, fluid flows in one-direction as illustrated in part (a) of Fig. 1. The bidirectional flow condition is illustrated in part (b) of Fig. 
1 where fluid flows back and forth in oscillatory manner. The oscillation of flow depends on frequency. The higher the frequency of flow, the more rapid the oscillation changes with time. This study aims to experimentally investigate the change of heat transfer performance across tube banks due to the change of flow conditions.

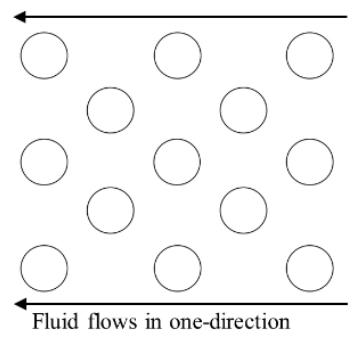

(a)

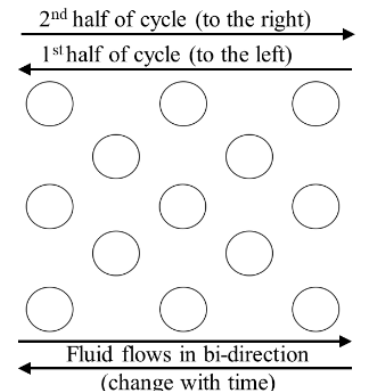

(b)
Fig. 1: Schematic diagram of (a) one-directional flow and (b) bi-directional flow condition

Since technological development must focus not only on the performance of the system but also on the technological impact on the environment, sustainable technologies like thermoacoustics should be given attention too $^{6}$. Thermoacoustics provides green technology for at least two major applications; cooling devices $^{15}$ and power generation equipment ${ }^{16,17)}$. Thermoacoustic technologies aim to offer alternative concepts for engines, coolers and heat pumps ${ }^{18)}$. In the presence of an acoustic wave and a porous structure, energy transfer could happen between a compressible fluid and a solid boundary of the porous structure and a thermodynamics cycle of power or refrigeration could be obtained under certain strict conditions ${ }^{6,8}$. The proper phasing between the acoustically induced fluid displacement and its compression or expansion, combined with the heat transfer between both solid and fluid, would result in the application of Stirling-like thermodynamic cycle that can provide efficient operation. The use of harmless working fluids such as argon, helium or some other inert gaseous as a working medium provides an advantage as it offers environmentally friendly operation and benefits to the technologies ${ }^{18)}$. As with all other energy systems, heat exchanger is the most important part of the system and it plays a significant role in maintaining the temperature different that is required to be sustained within the system. Heat exchangers can be generally defined as instruments that can be used at varying temperatures to transfer energy between two fluids ${ }^{19)}$. The growing imperative to conserve electricity and decrease the potential environmental effects has put greater focus on the use of heat exchangers with improved thermal performance in the modern age of sustainability ${ }^{20)}$. Errors in prediction or calculation of heat transfer may lead to errors in estimating the performance of the systems ${ }^{12}$. The imperfect formulation of heat transfer could also lead towards error between theoretical predictions and real values as can be seen reported in a published research work $^{21)}$. In oscillatory flow condition, which is defined in this work as a bi-directional flow condition, the fluid flows back and forth following cyclic nature of the flow ${ }^{18)}$. In the presence of an object, like a heat exchanger, the flow will be disrupted in ways different compared to the normal one-directional flow condition. The appearance of early stage turbulence ${ }^{22)}$, two thermal entrance region ${ }^{23)}$ and nonlinearity of flow $^{24}$ indicate that the established heat transfer correlation from one-directional flow condition may not be simply used for bi-directional flow environment. For most situations, the fluid dynamics of the air that flows over the tube banks is unique due to the presence of tube bundles and thus could not be simply solved by equation for a steady flow through one object. The effort of modeling the fluid behavior for bi-directional flow conditions of several Stoke's Reynolds number cases revealed that turbulence begins when Reynolds is between 70 and 100 as the fluid flows back and forth across structures within the thermoacoustic system ${ }^{28)}$. This implies that the impact of heat transfer across tube banks in bi-directional flow would not be the same as onedirectional flow over the structure. Some investigations have been reported on heat transfer across heat exchanger in bi-directional flow condition of thermoacoustic. The role for additional parameter such as thermal penetration depth (i.e., thermal boundary layer), length of structure, porosity of heat exchanger (i.e., blockage ratio), and flow frequency on heat transfer performance of the heat exchanger have been detected in published works related to oscillatory or bi-directional flow conditions ${ }^{25,} 26$. However, investigating heat transfer in such complicated environments could not be done easily by looking at all the parameters all at once. The changes need to be looked at by considering one factor at a time. Hence, this study reported the first part of the investigation where heat transfer is going to be compared between one-directional flow condition and the bi-directional flow condition. The results to be shown here will open more doors for a deeper investigation of heat transfer within bi-directional flow condition which will be benefited by many technologies that work under such environment.

\section{Experimental setup}

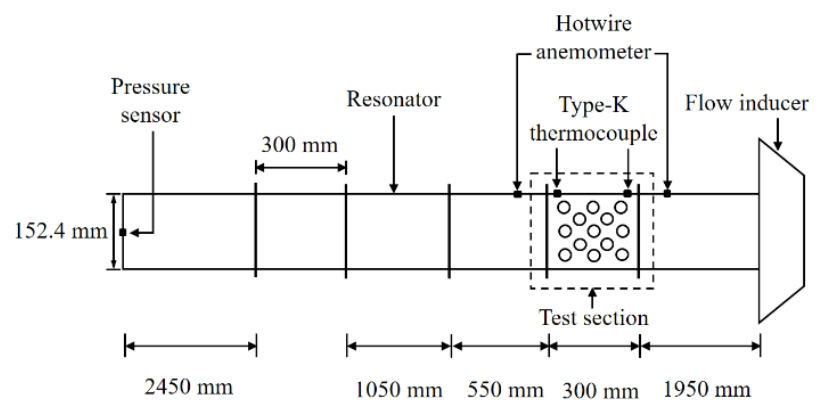

Fig. 2: Schematic diagram of experimental setup 
The experimental works are designed so that comparison can be done between heat transfer performances of one-directional and bi-directional flow conditions over a tube bank. Fig. 2 showed the schematic diagram of the experimental setup.

The experimental setup involves the use of flow inducer that is attached to a hollow steel tube. The flow inducer is changed depending on the flow to be induced in the rig. A blower is used for one-directional flow condition and a loudspeaker is used for bi-directional flow condition. The steel tube that is used as the flow passage in the experiment is the one that was built for the study of standing wave thermoacoustic environment ${ }^{27)}$. This setup is based on the thermoacoustic's quarter wavelength resonator $^{28)}$. The rig consisted of a $6.6 \mathrm{~m}$ long resonator that is attached to a loudspeaker (PD 1860). The resonator's cross-sectional area is $152.4 \mathrm{~mm} \times 152.4 \mathrm{~mm}$ and the wall thickness of $4 \mathrm{~mm}$. The loudspeaker that was used as the flow inducer for the bi-directional flow (i. e., oscillatory flow) is as shown in Fig. 3.

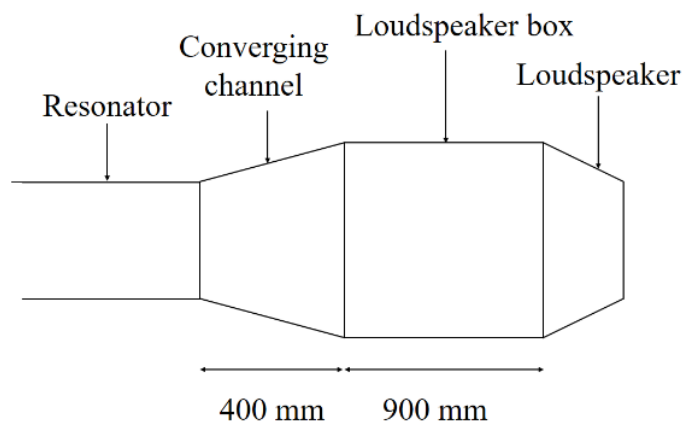

(a)

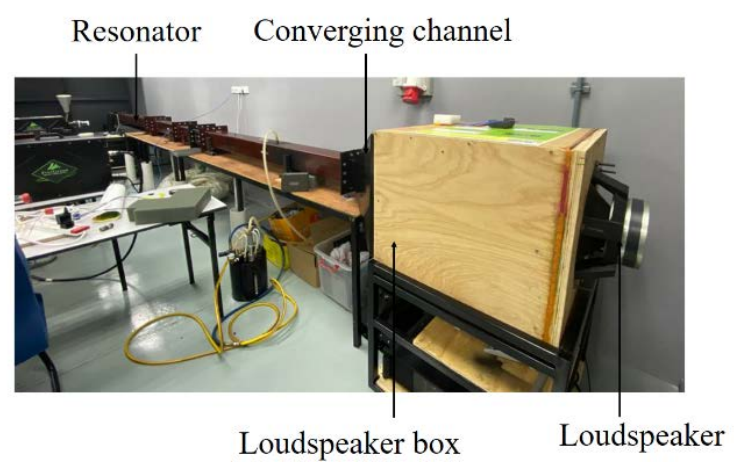

(b)

Fig. 3: (a) Schematic diagram and (b) the real diagram of the loudspeaker as a flow inducer.

The loudspeaker is controlled by a function generator (AFG 21005) and an amplifier (FLP-MT1201) that are attached to it. The amplitude of the bi-directional flow condition is controlled by setting the input voltage through the function generator. The frequency of the flow is kept constant at a resonance value.

The test section, as shown in Fig. 4, is placed at a location of $0.186 \lambda$ from the pressure antinode. The pressure antinode is a location where pressure amplitude is maximum. For the quarter wavelength resonator, the location of pressure antinode is at the hard end of the resonator (i.e., the leftmost end of Fig. 2). The working fluid is air at atmospheric temperature. For this condition, the wavelength, $\lambda=c / f$ (where $c$ is the speed of sound for air in $\mathrm{m} / \mathrm{s}$ and $f$ is the frequency in $\mathrm{Hz}$ ) can be determined to be $24.15 \mathrm{~m}$. Hence, the test section is placed at a location $4.5 \mathrm{~m}$ from the hard end of the resonator.

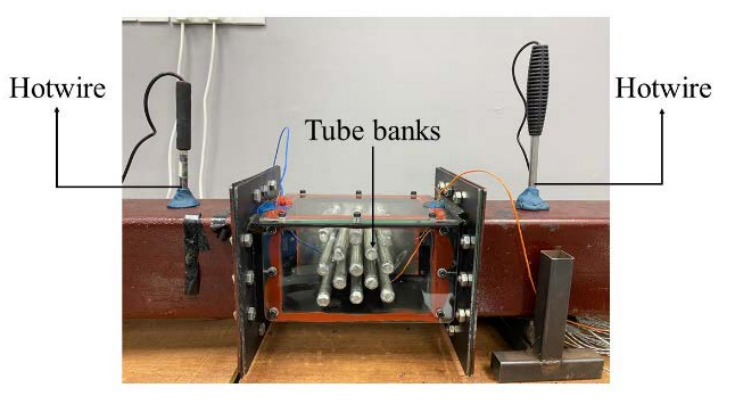

Fig. 4: Test section

A piezoresistive pressure sensor (Endevco 8510B-2) is flushed mounted on that hard end of the rig to monitor the value at that end. A 13 Volt voltage supply is used to control the input voltage of the pressure sensor and the output voltage of the pressure sensor is sensed by a DATAQ data logger (DI-718B) with the use of an amplifier (DI-8B31-01). This signal is then recorded by Windaq software that is installed in a computer.

The amplitudes of flow that is induced by the loudspeaker are recorded at two locations before and after the test section area. The location is as shown in Fig. 4. A hot wire anemometer (ST-732) was used to measure the amplitude of the flow. The hotwire is placed at the two different locations to measure the velocity at the inlet, $V_{\text {in }}$, and the outlet, $V_{\text {out }}$, of the test section. The same location of hotwire measurement is also applied for bi-directional flow condition.

For the purpose of data comparison, the similar rig was used for the test of heat transfer of one-directional flow across a tube bank. Only this time a high-pressure ring blower (AIRSPEC ARC 269 (3)) is used to replace the loudspeaker. The blower, as shown in Fig. 5, supplies flowing air into the resonator. The hard end on the pressure antinode location is left open to allow flow to stay in one-directional along the process. A convergingdiverging channel with an embedded flow straightener is used to connect the blower to the resonator. Preliminary data was collected to calibrate the flow that is induced by the two flow inducers (i.e., loudspeaker and blower) and the best conditions for comparison were selected. For this heat transfer study, a staggered tube banks heat exchanger was designed and placed in the test section area. The tube bank heat exchanger is as shown in Fig. 6.

The heat exchanger was build using aluminum tubes of $20 \mathrm{~mm}$ outer diameter and $3 \mathrm{~mm}$ wall thickness. Although copper was usually used for heat exchanger, but aluminum was used in this experiment due to availability and ease of 


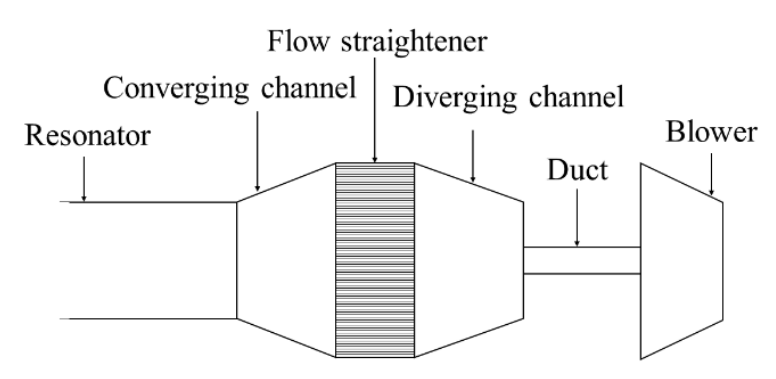

$280 \mathrm{~mm} 100 \mathrm{~mm} 300 \mathrm{~mm} 300 \mathrm{~mm}$

(a)

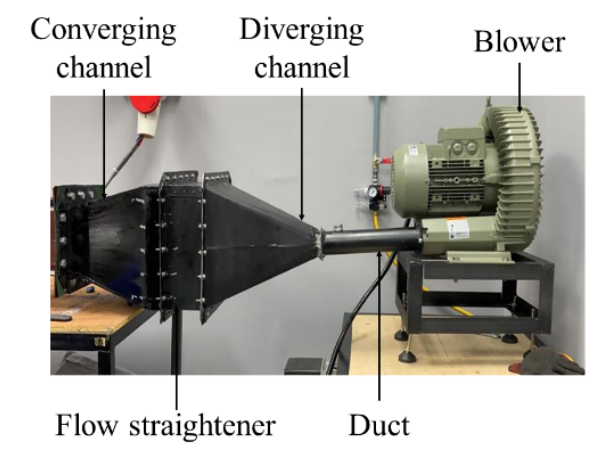

(b)

Fig. 5: (a) Schematic diagram and (b) the real equipment of the blower as a flow inducer.

fabrication. Since the experimental study is fixed at constant value of surface temperature, the choice of material will not give significant impact on the convective heat transfer between the surface of the tube and the external flow conditions. Hence the use of aluminum for the purpose of current investigation is justified. Thirteen tubes were arranged in staggered arrangement with horizontal length, $S_{L}$, of $45 \mathrm{~mm}$, a transverse length, $S_{T}$, of $22.5 \mathrm{~mm}$ and the diagonal length, $S_{D}$, of $31.82 \mathrm{~mm}$.

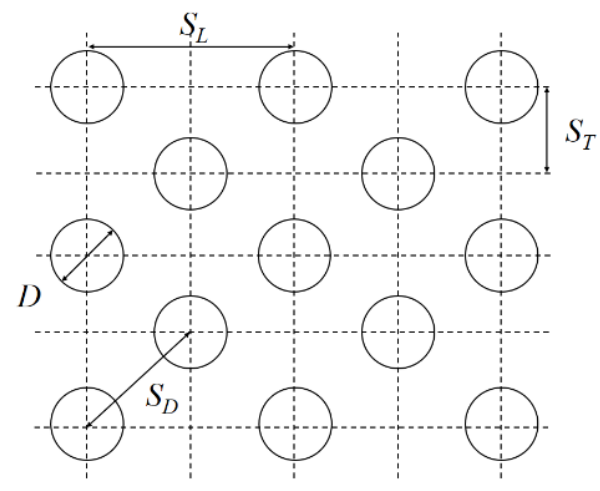

Fig. 6: Staggered tube bundles arrangement

The tubes were welded on an aluminum plate which is then screwed onto the back side of the test section area. The joints between all the connectors and flanges are sealed using rubber mat and high temperature adhesive (Hardex) whenever possible. Fig. 7 shows the schematic diagram of the tube heaters that are inserted inside all the staggered tubes.

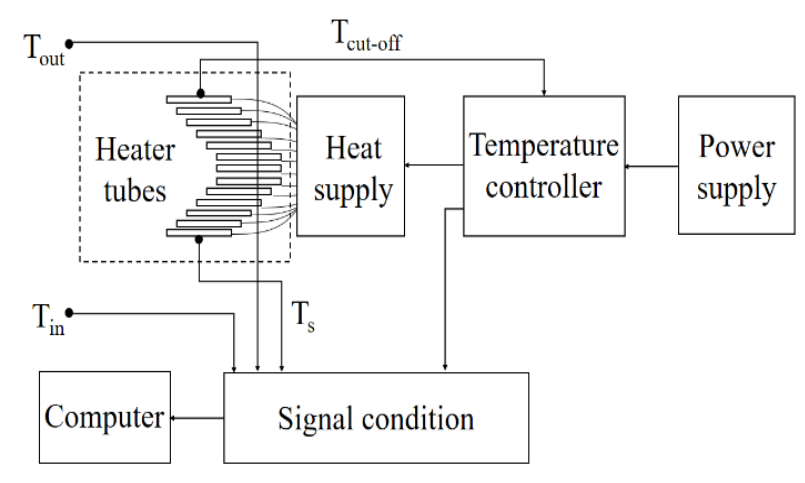

(a)

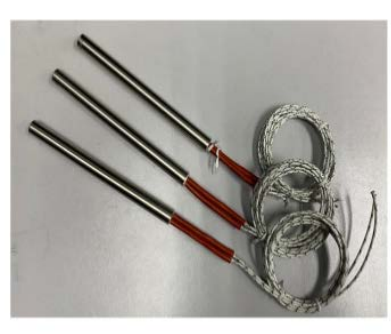

(b)

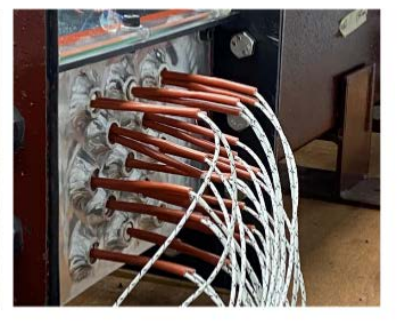

(c)
Fig. 7: (a) Schematic diagram of heater tubes connection, (b) the heater tubes and (c) the heater tubes that are inserted into tube banks through the back side of the test section

The input voltage to the heater is supplied via an inhouse control circuit that was built with the ability to control the tube temperature by controlling the supply of current to the heater. The temperature of the tube is monitored by a type-K thermocouple that is connected to a Picolog signal conditioner (TC 08). The signal from the signal conditioner is read and stored in a computer.

Experiments were done for two different values of surface temperature: $T_{s}=40^{\circ} \mathrm{C}$ and $T_{s}=80^{\circ} \mathrm{C}$. Due to the limitation of the available instruments, data can only be collected at the maximum surface temperature of $T_{s}=$ $80^{\circ} \mathrm{C}$. Observations during experimentations showed that when the temperature at the surface is more than $80^{\circ} \mathrm{C}$, the velocity of fluid will exceed the limitation of the hot wire measurement and therefore data could not be recorded. The surface temperature is monitored by a type-K thermocouple that is attached to one of the tube's surface. Another type-K thermocouple is used to supply data for the cut-off circuit that control the electric supply so that surface temperature can be maintained. The amplitude of flow is varied using the two flow inducers and data are collected based on variation of flow amplitudes that is monitored based on the reference location that is set at 120 $\mathrm{mm}$ to the right of the test section (closer to the flow inducer). This location is named as inlet location with velocity measured and defined as $V_{\text {in }}$. A thermocouple is 
also placed at this location to record the temperature known as inlet temperature, $T_{\text {in }}$. In order to understand the impact of flow on heat transfer across tube banks, measurement of velocity and temperature are also done at another location of $120 \mathrm{~mm}$ to the left side of the test section (towards the hard end of the resonator). These values are known as outlet velocity, $V_{\text {out }}$, and outlet temperature, $T_{\text {out }}$.

\section{Results}

\subsection{Resonance frequency}

For bi-directional flow condition, the experimental rig must first be tested for its resonance frequency. For this purpose, measurement was done by collecting data of pressure amplitude at the location of pressure antinode when the frequency is increasing in $0.1 \mathrm{~Hz}$ decimal while flow is kept constant at lowest amplitude. In this experiment the lowest amplitude was obtained at peak-topeak voltage setting, $V_{p p}$, of $0.08 \mathrm{~V}$. The results are as shown in Fig. 8.

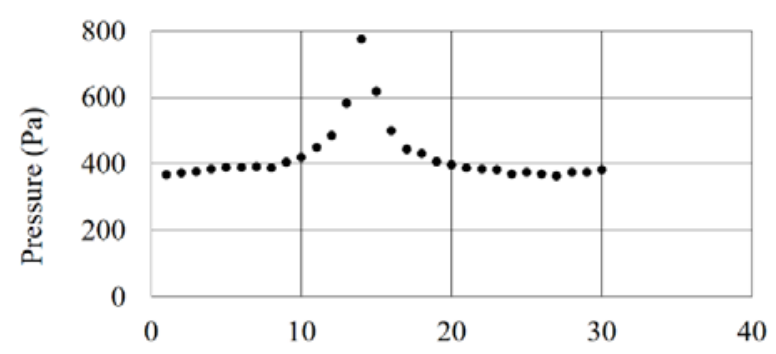

Fig. 8: Resonance frequency

The resonance frequency of the resonator is achieved when the peak value of pressure at location of antinode is observed in the experiment. The results show that the resonance frequency is $14.2 \mathrm{~Hz}$. This frequency is then used as a constant value to be set for frequency of the loudspeaker when the bi-directional flow is induced into the resonator.

\subsection{The calibration of flow using two different flow inducers}

Once resonance frequency of the rig is known, the experimentation is continued with calibration of the rig with two different flow inducers. The calibration of flow is done in the condition where heater is turned off. This means that the tube banks are present in the rig but without the supply of heat. As stated earlier, the experiments involved the use of two different flow inducers: the loudspeaker and the blower. For ease of comparison, data of velocity are collected at similar locations within the resonator when different flow inducers are used. The results are as shown in Fig. 9. The one directional flow experimentations were done with blower's frequency that is set to change from the minimum value of $4 \mathrm{~Hz}$ to a maximum of $50 \mathrm{~Hz}$. These values are selected based on the capacity and limitation of the blower and the rig. It is found that the highest velocity recorded at the location of $V_{\text {in }}$ is $4.04 \mathrm{~m} / \mathrm{s}$. For bi-directional flow condition, the loudspeaker is set to a constant frequency of $14.2 \mathrm{~Hz}$ and the peak-to-peak voltage that is supplied by the function generator is set to vary from $0.02 \mathrm{~V}$ to $0.45 \mathrm{~V}$. The resulting velocity at the location of $V_{i n}$ is found to vary from $0.57 \mathrm{~m} / \mathrm{s}$ to $6.74 \mathrm{~m} / \mathrm{s}$. For the purpose of comparison between data to be collected for one-directional and bidirectional flow conditions, this location of $V_{\text {in }}$ is set as a reference point for experimental works. Data should be collected based on the matched values of $V_{\text {in }}$ between onedirectional and bi-directional flow conditions so that fair comparison of results can be done. From this calibration exercises, the experimentation for heat transfer investigation is set to vary based on values of $V_{\text {in }}$ that ranges between $0.5 \mathrm{~m} / \mathrm{s}$ to $4 \mathrm{~m} / \mathrm{s}$.

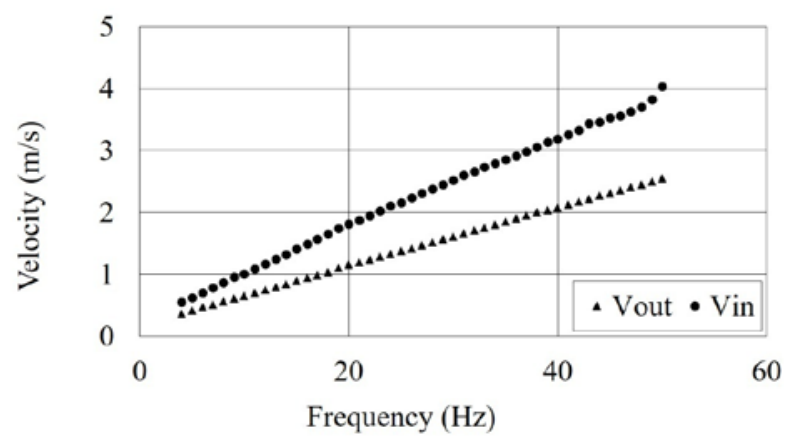

(a)

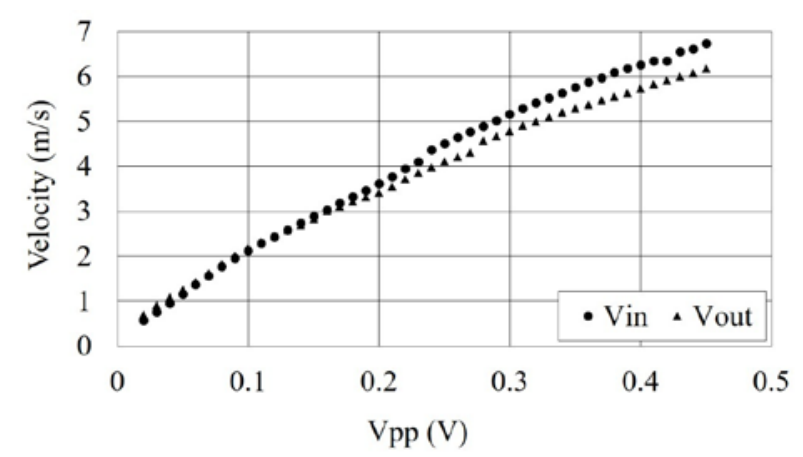

(b)

Fig. 9: Velocity changes at inlet and outlet location of the test section as (a) frequency of the blower increases (b) peak-to-peak voltage input of the loudspeaker increases.

\subsection{Temperature changes of flow across heater.}

In this section, the results of temperature measurement are shown. This measurement was recorded when the heater for the tube banks is turned on. Data are presented for two different values of surface temperature, (a) $T_{s}=$ $40^{\circ} \mathrm{C}$ and (b) $T_{s}=80^{\circ} \mathrm{C}$. Temperature data for onedirectional flow condition is recorded when blower is used as flow inducer. Temperature data for bi-directional flow condition is measured when the loudspeaker is used as a flow inducer. The temperature values are recorded at 
locations of $120 \mathrm{~mm}$ to the left and right sides of the test section (the same location of $V_{\text {in }}$ and $V_{\text {out }}$ ). The results are as shown in Fig. 10 and Fig. 11.

As expected, for one-directional flow condition, the temperature at outlet, $T_{\text {out }}$, which is in downstream location is always higher than the temperature at inlet, $T_{i n}$, due to the supply of heat by the tube banks heat exchanger. This trend can be seen in both the surface temperature, $T_{s}$, of $40^{\circ} \mathrm{C}$ and $80^{\circ} \mathrm{C}$ as shown in Fig. 10 . The downstream temperature at outlet, $T_{\text {out }}$, is also seen reducing as velocity of the flow increases. It is interesting to note that there is a noticeable drastic change of downward trend of temperature when $V_{\text {in }}$ is lower than $1 \mathrm{~m} / \mathrm{s}$. After the velocity of $1 \mathrm{~m} / \mathrm{s}$, the outlet temperature is almost constant and the reduction in value (if any) is relatively small. The same situation can be seen for inlet temperature of $T_{\text {in }}$. The change of $T_{\text {in }}$ value is more prominent at lower range of $V_{\text {in }}$. As $V_{\text {in }}$ reaches $1 \mathrm{~m} / \mathrm{s}$ the $T_{\text {in }}$ value is approximately the same. A slight increment of $T_{\text {in }}$ temperature can be seen for tube with surface temperature of $40^{\circ} \mathrm{C}$ especially at $V_{\text {in }}$ that is higher than $3.5 \mathrm{~m} / \mathrm{s}$.

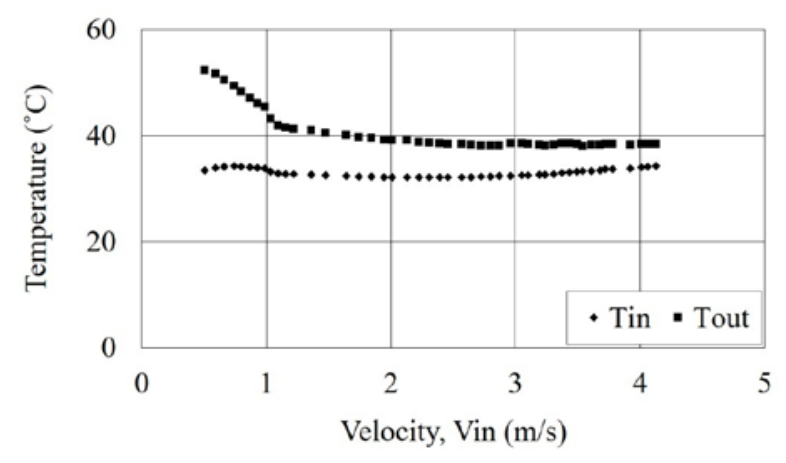

(a)

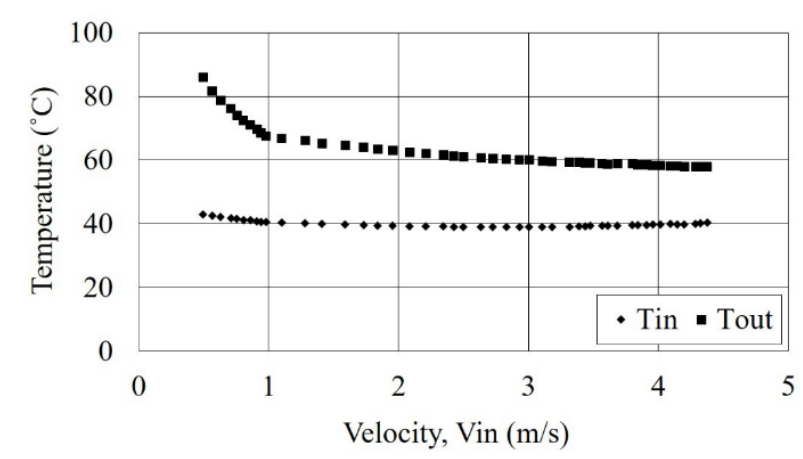

(b)

Fig. 10: Temperature changes with inlet velocity in onedirectional flow condition at a heated tube surface temperature of (a) $40^{\circ} \mathrm{C}$ and (b) $80^{\circ} \mathrm{C}$

The interesting drastic change of temperature pattern at $V_{\text {in }}$ of approximately $1 \mathrm{~m} / \mathrm{s}$ indicates the feature of balance between natural and forced convection that happens at that stage. At lower $V_{\text {in }}$, natural convection current is still strong and as $V_{\text {in }}$ increases forced convection impact is more prominent. The fluid is forced to flow at higher speed, and it will pick up heat consistently as it flows. So, it can be fairly said that the flow is thermally developed when $V_{\text {in }}$ is higher than $1 \mathrm{~m} / \mathrm{s}$. In thermally developed region, a more consistent temperature drop can be observed within the test section area (i.e., the area of the tube banks).

Fig. 11 shows the temperature changes with the change of input velocity when the flow is bi-directional. It is quite interesting to note that the value of temperature at the locations of inlet and outlet are approximately the same. The bi-directional flow condition of this investigation is the oscillatory flow of thermoacoustics where fluid flows back and forth across the tube banks. The cyclic flow never really leaves the system and therefore be heated by the heater as the fluid oscillates back and forth across the heater. It is also observed that the temperature values at inlet and outlet locations are approximately constant at around $48^{\circ} \mathrm{C}$ as velocity increases. It seems that the temperature of flow remains almost constant even when the momentum of flow changes.

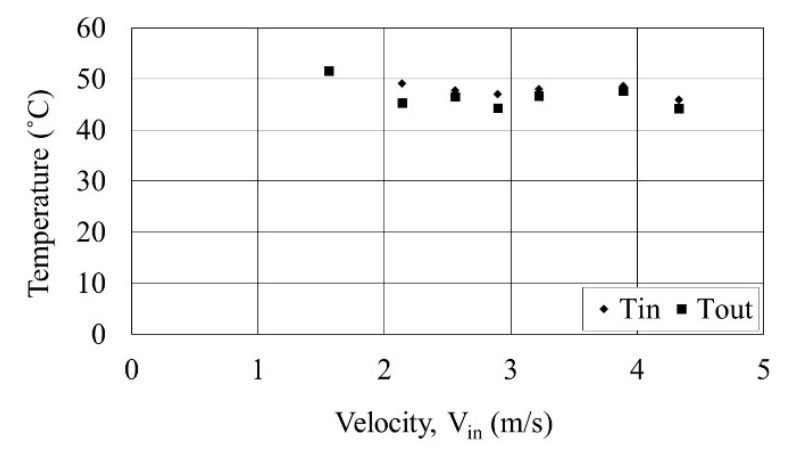

(a)

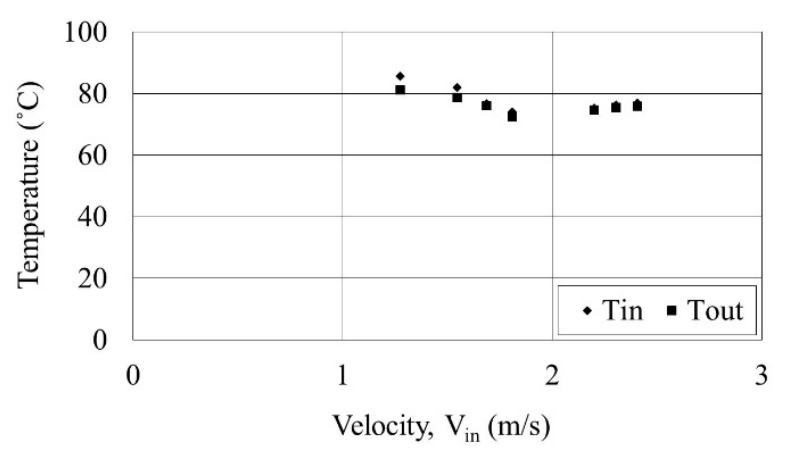

(b)

Fig. 11: Temperature changes with inlet velocity in bidirectional flow condition at a heated tube surface temperature of (a) $40^{\circ} \mathrm{C}$ and (b) $80^{\circ} \mathrm{C}$

For the case of higher surface temperature $\left(T_{s}=80^{\circ} \mathrm{C}\right)$, temperature at both the locations at inlet and outlet are decreasing as velocity of the bi-directional flow increases up to about $2 \mathrm{~m} / \mathrm{s}$. After that, the value of temperature is almost constant. Similar to the case with $T_{s}=40^{\circ} \mathrm{C}$, the fluid temperature for cases with $T_{s}=80^{\circ} \mathrm{C}$ at locations of inlet and outlet are approximately the same. The transient feature of flow, as seen in the low flow amplitude of one- 
directional flow condition, is only seen for bi-directional flow cases with $T_{s}=80^{\circ} \mathrm{C}$.

Comparison of results of temperature between onedirectional and bi-directional flow conditions can be done by comparing the results of Fig. 10 and Fig. 11. The most prominent differences between temperature plots of Fig. 10 and that of Fig. 11 is the difference in $T_{\text {in }}$ and $T_{\text {out }}$. In one-directional flow condition (i.e. Fig. 10), the temperature at inlet and outlet locations of the test section is different. However, for bi-directional flow condition (i.e. Fig. 11) the temperature values at these two locations are almost the same.

\subsection{Velocity changes of flow across heater.}

The presence of heat will lead towards changes of fluid dynamics of flow. Hence, velocity data are recorded again for both the one-directional and bi-directional flow conditions with the presence of heated tubes. The results are as shown in Fig. 12 and Fig. 13.



(a)

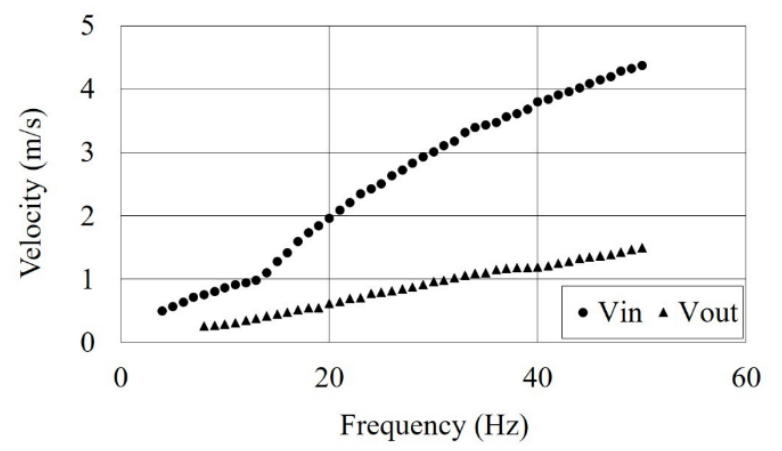

(b)

Fig. 12: Velocity changes with flow amplitude (recorded as frequency of the blower) in one-directional flow condition at a heated tube surface temperature of (a) $40^{\circ} \mathrm{C}$ and (b) $80^{\circ} \mathrm{C}$

Fig. 12 showed the velocity changes as the amplitude of one-directional flow changes. It is observed that the velocity increases as frequency of the blower is increasing. In general, the velocity amplitude at inlet (upstream location) is bigger than the velocity of the flow at the outlet (downstream location). This is logical since the inlet location is closer to the blower. The transient feature of the flow at low input of blower's frequency is consistent with the transient data of temperature as shown in Fig. 10.
As the tube surface temperature increases from $T_{s}=40^{\circ} \mathrm{C}$ to $T_{s}=80^{\circ} \mathrm{C}$, the difference between $V_{\text {in }}$ and $V_{\text {out }}$ becomes bigger. This can be seen as a diverging difference between the $V_{\text {in }}$ and $V_{\text {out }}$ data as frequency increases. It is also observed that the amplitude of $V_{i n}$ is bigger and the amplitude of $V_{\text {out }}$ is lower when $T_{s}$ is higher. This may be related to the combined effect of natural convection and forced convection. It seems that the buoyant force of natural convection is helping the flow at inlet but resisting the flow at outlet. This is logical as the buoyant force of the natural convection is expected to be bigger near the test section area. At inlet location, the forced flow is still bigger and undisturbed. In the downstream location, the flow amplitude not only decreases but was also disturbed by the potential presence of turbulence and distortion of flow as fluid flows past the tube bank's structure. This could lead to weaker forced flow influence and therefore the impact of buoyancy force of natural convection current (flow resistance) is felt more at that location. The impact of natural convection current is also seen in the results of bi-directional flow as shown in Fig. 13.

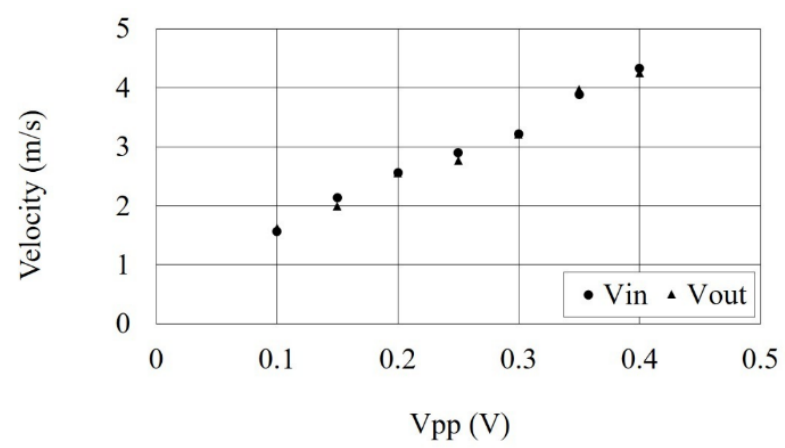

(a)

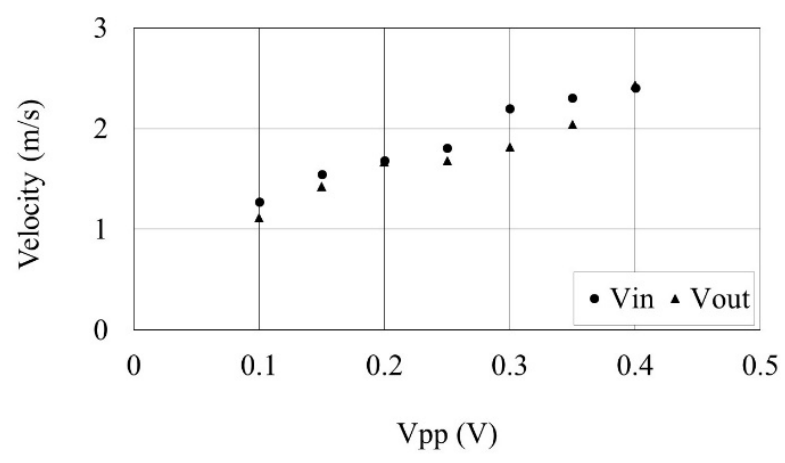

(b)

Fig. 13: Velocity changes with flow amplitude (recorded as $V_{p p}$ of the loudspeaker) in bi-directional flow condition at a heated tube surface temperature of (a) $40^{\circ} \mathrm{C}$ and (b) $80^{\circ} \mathrm{C}$

For bi-directional flow, the inlet and outlet locations are at one time the entrance and at another time the exit points for the fluid flow. The fluid flows to the left during first half of the cycle and then to the right during the second half of the cycle. The cycle repeated depending on the frequency of the flow. As a result, fluid velocities at the 
left $\left(V_{\text {out }}\right)$ and the right $\left(V_{\text {in }}\right)$ sides of the test section appear almost similar. The velocity increases with an increase of supplied voltage $\left(V_{p p}\right)$. The impact of natural convection can be seen by comparing the results for $T_{s}=40^{\circ} \mathrm{C}$ and $T_{s}$ $=80^{\circ} \mathrm{C}$ (shown as plots (a) and (b) in Fig. 13, respectively). For $T_{s}=40^{\circ} \mathrm{C}$, the velocity was recorded within the range of $1.56 \mathrm{~m} / \mathrm{s}$ until $4.33 \mathrm{~m} / \mathrm{s}$ which is equivalent to Reynolds number between 80 and $350(80<\mathrm{Re}<350)$. However, for $T_{s}=80^{\circ} \mathrm{C}$, the velocity values were recorded to range between $1.275 \mathrm{~m} / \mathrm{s}$ and $2.405 \mathrm{~m} / \mathrm{s}$. These values are corresponding to Reynolds number of $50<\mathrm{Re}<200$. The range of Reynolds for the tested flow conditions are within the range of early-stage turbulence as reported in published work ${ }^{22)}$. Hence, the influence of turbulence could be expected. The results shown in Fig. 13 showed that the amplitude of velocity decreases when the tube surface temperature increases. When tube banks surface temperature is higher, more heat is supplied to the fluid and therefore the natural convection current is stronger. The natural convection current is resisting the main flow. As a result, the amplitude of flow is lower in the case of $T_{s}=80^{\circ} \mathrm{C}$.

Comparison of velocity between one-directional and bidirectional flow conditions can be done by comparing the results of Fig. 12 and Fig. 13. One prominent feature of bi-directional flow condition is that the velocity amplitudes at locations of $120 \mathrm{~mm}$ to the left $\left(V_{\text {out }}\right)$ and right sides $\left(V_{i n}\right)$ of the test section are almost the same. The natural convection current is resisting the flow in both sides of the test section. In one-directional flow, the natural convection is assisting the flow in the upstream location $\left(V_{\text {in }}\right)$ and it resists the flow only at downstream location $\left(V_{\text {out }}\right)$. It is clear that the one-directional and bidirectional flow conditions lead to different fluid dynamics feature and therefore the heat transfer performance may be impacted as well. The current investigation showed that there are differences seen between the two types of flow based on temperature and velocity changes within the fluid as the fluid flows across tube banks heat exchanger. This indicates that heat transfer of flow across tube banks in one-directional flow condition is not the same as that in the bi-directional flow condition. Further investigation into this matter will be needed to confirm the details of physics that lead toward the difference of results as observed in the current investigation.

\section{Conclusion}

An experimental method for the investigation of temperature and velocity changes when fluid flows across tube banks heat exchanger was devised for two different conditions: one-directional flow condition and the bidirectional flow condition (oscillatory flow of thermoacoustics). The results can be concluded as follows:

a) Temperature and velocity values at upstream and downstream locations of the one-directional flow condition are different and the maximum difference that was recorded between the two locations when flow is one-directional (for the range of data tested in this experiment) are shown to be at $23 \%$ and $50 \%$, respectively. However, for bi-directional flow conditions (oscillatory flow of thermoacoustics), the temperature and velocity at these two locations are almost similar. The differences of values of temperature and velocity between the two flow conditions (bi-directional versus one-directional) are recorded to be at $77 \%$ and $59.5 \%$, respectively.

b) The combined effect of natural convection and forced convection of flow across heated tube banks depends on flow condition. In one-directional flow condition, the combined effect assist the flow in upstream location but resisting the flow in downstream location. For bi-directional flow condition, the combined effect of natural and forced convection is resisting the flow in both the upstream and downstream locations.

The impact of the difference in behavior of change for temperature and velocity data of flow across tube banks on heat transfer performance when the fluid flow over tube banks changes its behavior can be illustrated via the role of velocity and temperature in calculating the heat transfer between the tubes and the fluid outside the tube. Based on the well-established calculation method for onedirectional flow condition, heat transfer, $Q$, can be calculated based on heat transfer coefficient, $h$, the surface area, $A$, and the log-mean-temperature difference $\Delta T_{L M T D}{ }^{19)}$. The heat equation can be written as $Q=$ $h A\left(\Delta T_{L M T D}\right)$ where $\Delta T_{L M T D}$ is a function of temperature different values at the inlet and outlet with respect to the surface temperature of the tube. The heat transfer coefficient, $h$, depends on the velocity of the flow at the inlet as well as outlet locations of the tube banks. Clearly, the temperature and velocity values at the inlet and outlet locations are important aspect in calculating external heat transfer of flow over tube banks. The results reported in this paper confirmed that the trend of temperature changes at these two different locations of inlet and outlet are not similar when fluid flows in two different flow conditions. Hence, the use of the well-established heat equation for one-directional flow condition across tube banks may not be representing the real nature of heat transfer when fluid flows in bi-directional flow condition. The results reported here were only tested for one flow frequency of bi-directional flow condition. It is noted that thermoacoustic flow conditions can happen at different values of flow frequencies. Further comprehensive investigation will be needed to gain more understanding about the heat transfer of bi-directional flow condition over tube banks, especially in relation to thermoacoustic energy system environment. 


\section{Acknowledgements}

The preliminary numerical work of this study has been accepted and presented in MERD'20. The authors would like to thank Universiti Teknikal Malaysia Melaka for providing research facilities and this research is funded by the Ministry of Higher Education Malaysia (RACER/2019/FKM-CARE/F00407).

\section{Nomenclature}

$\begin{array}{ll}A & \text { heat flow area }\left(\mathrm{m}^{2}\right) \\ c & \text { speed of sound }(\mathrm{m} / \mathrm{s}) \\ f & \text { frequency }(\mathrm{Hz}) \\ h & \text { heat transfer coefficient }\left(\mathrm{W} / \mathrm{m}^{2} \cdot \mathrm{K}\right) \\ Q & \text { heat transfer }(\mathrm{W}) \\ S & \text { dimension of length }(\mathrm{m}) \\ T & \text { temperature }\left({ }^{\circ} \mathrm{C}\right) \\ \Delta T & \text { temperature difference }(\mathrm{K}) \\ V & \text { velocity }(\mathrm{m} / \mathrm{s})\end{array}$

Greek symbols

$$
\lambda \quad \text { Wavelength (m) }
$$

\section{Subscripts}

$\begin{array}{ll}D & \text { diagonal } \\ \text { in } & \text { inlet } \\ L & \text { horizontal } \\ \text { out } & \text { outlet } \\ T & \text { transverse }\end{array}$

\section{References}

1) T Watanabe, " Ignorance as a limitation for the application of scientific methods to environmental protection activities", Evergreen, 2 (1) 41-48 (2015). doi.org/10.5109/1500426

2) M. T. Kibria, M. A. Islam, B. B. Saha, T. Nakagawa and S. Mizuno, "Assessment of environmental impact for air-conditioning systems in Japan using HFC based refrigerants", Evergreen, 6 (3) 246-253 (2019). hdl.handle.net/2324/2349301

3) M. A. Islam, A. Pal, K. Thu, B. B. Saha, " Study on performance and environmental impact of supermarket refrigeration system in Japan", $\begin{array}{llll}\text { Evergreen, } & 6 & \text { (2), } & \text { 168-176 }\end{array}$ hdl.handle.net/2324/2321014

4) N. A. Lestari, "Reduction of $\mathrm{CO}_{2}$ emission by integrated biomass gasification-solid oxide fuel cell combined with heat recovery and in-situ CO2 utiliszation", Evergreen, 6 (3) 254-261 (2019). hdl.handle.net/2324/2349302.

5) S. M. Ali and A. Chakraborty, " Peformance study of adsorption cooling cycle for automotive airconditioning", Evergreen, 2 (1) 12-22 (2015). doi.org/10.5109/1500423

6) M. A. Alamir, "Thermoacoustic Energy Conversion Devices: Novel Insights,” Journal of Advanced Researched in Fluid Mechanics and Thermal Sciences, 77, Issue 2 (2021) 130-144. http://www.akademiabaru.com/submit/index.php/arf mts/article/view/806/1103

7) A. S. Pamitran, Novianto S., Mohd-Ghazali N., Koestoer R. A., "Flow pattern of two-phase flow boiling with heat transfer and pressure drop using natural refrigerant (propane) in microchannel", Evergreen, $7 \quad$ (4) $544-548 \quad$ (2020). doi.org/10.5109/4150474

8) N. A. Zolpakar, N. Mohd-Ghazali, and M. H. ElFawal, " Performance analysis of standing wave thermoacoustic refrigerator: A review", Renew. Sust. Energ., $\quad 54 \quad 626-634 \quad$ (2016). dx.doi.org/10.1016/j.rser.2015.10.018

9) H. G. Ramírez-Hernández, F. A. Sánchez-Cruz, F. J. Solorio-Ordaz, S. Martínez-Martínez, " An experimental study of heat transfer on a tube bank under frost formation conditions. Int. J. Refrig., 102, 35-46 (2019). doi.org/10.1016/j.ijrefrig.2019.01.031

10) A. K. Nagavarapu, S. Garimella, "Experimentally validated models for falling-film absorption around microchannel tube banks: Heat and mass transfer", Int. J. Heat Mass Transfer, 139, 303-316 (2019). doi.org/10.1016/j.ijheatmasstransfer.2019.05.024

11) S.A. Gabriel, Y. Ding, Y. Feng, "Quantifying the influence of oscillatory flow disturbances on blood flow, J. Theor. Biol., 430, 195-206 (2016). doi.org/10.1016/j.jtbi.2017.07.008

12) A. A. Rahman, X. Zhang, "Prediction of oscillatory heat transfer coefficient for a thermoacoustic heat exchanger through artificial neural network technique", Int. J. Heat Mass Transfer, 124, 10881096 (2018). doi.org/10.1016/j.ijheatmasstransfer.2018.04.035

13) A. Alberto, M. Onorato, F. Frascoli, A. Toffoli, "Observation of turbulence and intermittency in wave-induced oscillatory flows", Wave Motion, 84, 81-89 (2019). doi.org/10.1016/j.wavemoti.2018.10.003.

14) F. Xin, Z. Liu, P. Liu, W. Liu, "Numerical study on flow characteristics and heat transfer enhancement of oscillatory flow in a spirally corrugated tube", Int. $J$. Heat Mass Transfer, 127, 402-413 (2018). doi.org/10.1016/j.ijheatmasstransfer.2018.06.139

15) E. M. Sharify, and S. Hasegawa, "Travelling-wave thermoacoustic refrigerator driven by multistage travelling-wave thermoacoustic engine", Appl. Therm. Eng., 113, 791-795 (2017). doi.org/10.1016/j.applthermaleng.2016.11.021

16) M. Senga, and S. Hasegawa, " Energy conversion of thermoacoustic engines with evaporation and condensation", Int. J. Heat Mass Transfer, 165 Part B, 120385

(2021). 
doi.org/10.1016/j.ijheatmasstransfer.2020.120385

17) M. A. G. Timmer,K. de Blok, T. H. Van Der Meer, "Review on the conversion of thermoacoustic into electricity", J. Acoust. Soc. Am., 143, Issue 2 (2018) 10.1121/1.5023395

18) F. A. Z. Mohd Saat, "Thermoacoustic technology for renewable and sustainable energy systems; Malaysia perspective" in M. A. Salim and A. Md Saad, "Renewable Energy and Technology in Malaysia Perspective", Penerbit Universiti, Universiti Teknikal Malaysia Melaka, Malaysia (2019). https://shopee.com.my/Renewable-Energy-andTechnology-in-Malaysia-Perspective-Issues-andChallenges-i.225393594.7216772455

19) F. A. Z. Mohd Saat, S. Mihsa, N. S. Hamdan, M. A. Abdul Wahap, M. N. Othman, "Heat transfer", Malaysia, Penerbit Universiti, Universiti Teknikal Malaysia Melaka, Malaysia, 89 - 101 (2020). https://utembooks.utem.edu.my/shop/categoris/mod ul-pembelajaran-pengajaran/heat-transfer-detail.html

20) F. A. S. Mota, E.P. Carvalho, M. A. S. S. Ravagnani, "Modeling and design of plate heat exchanger," In Heat Transfer Studies and Applications. IntechOpen (2015). doi.org/10.5772/60885

21) K. O. A. Abdoulla-Latiwish, X. Mao, A. J. Jaworski, "Thermoacoustic micro-electricity generator for rural dwellings in developing countries by waste heat from cooking activities", Energy, 134, 1107-1120 (2017). doi.org/10.1016/j.energy.2017.05.029

22) F. A. Z. Mohd Saat, and A. J. Jaworski, "Numerical predictions of early stage turbulence in oscillatory flow across parallel-plate heat exchangers of a thermoacoustic system", Appl. Sci., 7, 673 (2017). doi.org/10.3390/app7070673

23) M. T. Pamuk, "A new heat transfer correlation for oscillating fluid flow,” Therm. Sci.., 22, 2459-2466 (2018). doi.org/10.2298/TSCI160126215P

24) K. Kuzuu, S. Hasegawa, "Effect of non-linear flow behavior on heat transfer in a thermoacoustic engine core", Int. J. Heat Mass Transfer, 108, Part B, 15911601 (2017). doi.org/10.1016/j.ijheatmasstransfer.2016.12.064

25) Ilori, O. M., Jaworski, A. J., and Mao, X., "Experimental and numerical investigations of thermal characteristics of heat exchangers in oscillatory flow”, Appl. Therm. Eng., 44, 910-925 (2018). doi.org/10.1016/j.applthermaleng.2018.07.073

26) Kamsanam W., Mao X., and Jaworski A.J., “Thermal performance of finned-tube thermoacoustic heat exchangers in oscillatory flow conditions", Int. J. Therm. Sci., 101, 169-180 (2016). doi.org/10.1016/j.ijthermalsci.2015.10.032

27) F. A. Z. Mohd Saat, D. Johari, E. Mattokit, "DeltaE Modelling and Experimental Study of a Standing Wave Thermoacoustic Test Rig”, Journal of Advanced Research in Fluid Mechanics and Thermal
Sciences 60, Issue 2, 155-165 (2019). http://www.akademiabaru.com/doc/ARFMT SV60_N2_P155_165.pdf

28) D. Johari, "Investigation of oscillatory flow behavior across internal structure in thermoacoustic refrigeration system” , MSc thesis, Universiti Teknikal Malaysia Melaka, Malaysia (2020). 